\title{
Erratum zu: Autologe Weichgewebstransplantate
}

Die Online-Version des Originalbeitrages ist unter doi: 10.1007/s12614-016-6260-8 zu finden.

In diesem Beitrag wurden leider die Abbildungen zu den Patientenfällen 1 und 2 vertauscht.

Die richtige Reihenfolge der Abbildungen ist hier dargestellt:

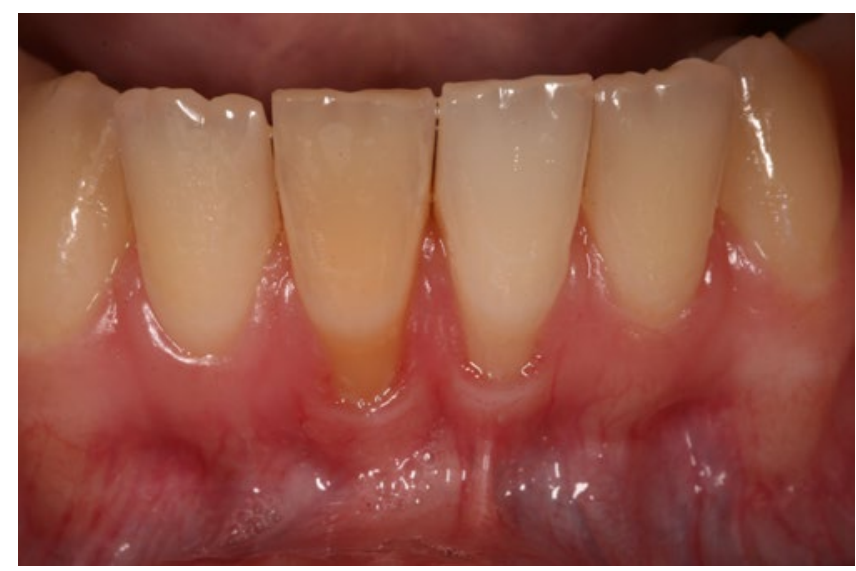

1 Erster Patientenfall. Rezessionen im ästhetisch nichtrelevanten Bereich. Sehr dünnes Weichgewebe, hoch einstrahlendes Bändchen und leichter Bukkalstand der Wurzeln der Zähne 31 und 41. Der Schwerpunkt der Behandlung liegt in der Schaffung einer Barriere mit einer ausreichend breiten Zone an keratinisierter Gingiva

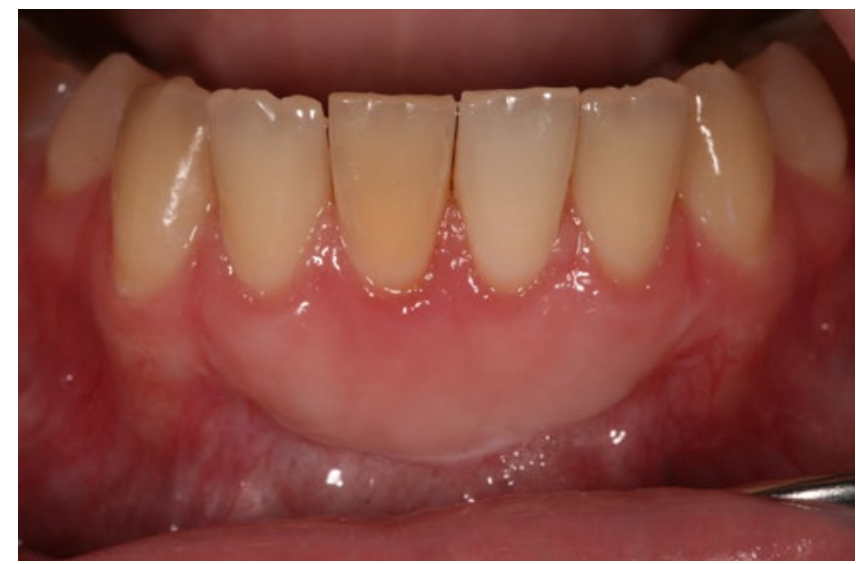

3 Erster Patientenfall. Vollständige Deckung der Rezession sowie deutliche Verbreiterung und Verdickung der Zone keratinisierter Gingiva nach einem Jahr Beobachtungszeit. Durch die Ausdehnung des Transplantats stellt der moderate Farbunterschied zu den Nachbarzähnen kein ästhetisches Problem dar

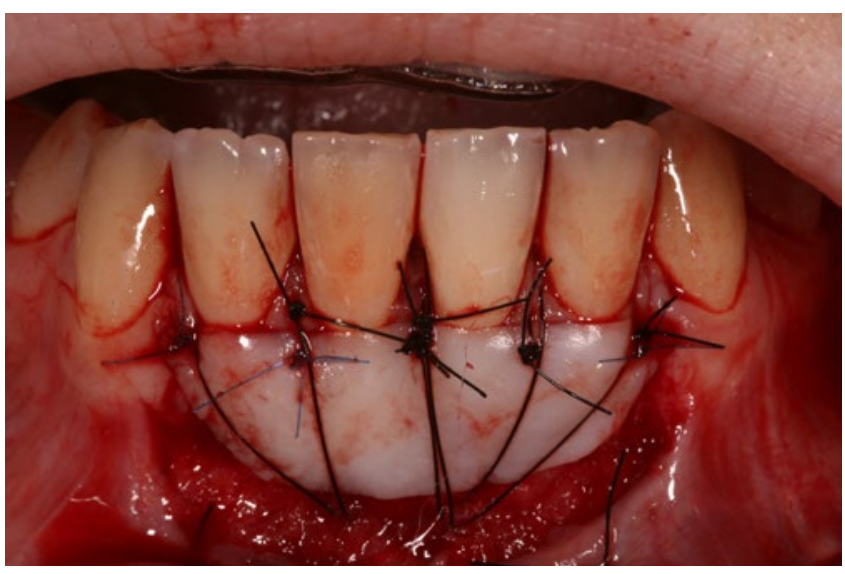

2 Erster Patientenfall. Vestibulumplastik mit supraperiostaler Präparation des Wundbetts und Deckung der freiliegenden Wurzelanteile mit einem freien Schleimhauttransplantat (FST). Das Transplantat wurde über den gesamten Frontzahnbereich ausgedehnt und passgenau an die Horizontalinzisionen im Papillenbereich adaptiert. Überknüpfungsnähte pressen das FST auf die ernährende Unterlage

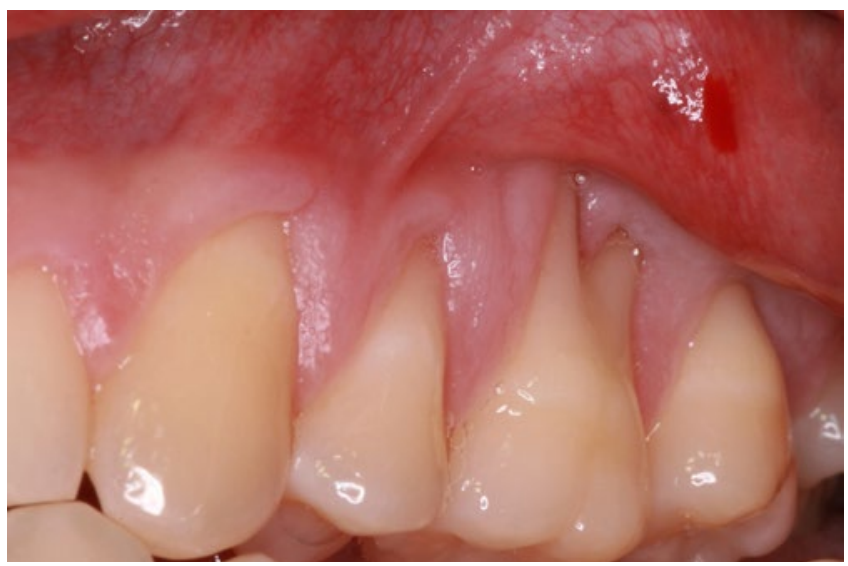

4 Zweiter Patientenfall. Rezessionen mit Bukkalstand der Wurzeln bei einem 19-jährigen Patienten (Zahn 25, Miller-Klasse III, Zahn 26 ausgeprägter Fehlstand und damit Rezession der Miller Klasse IV und freiliegende Furkation) 


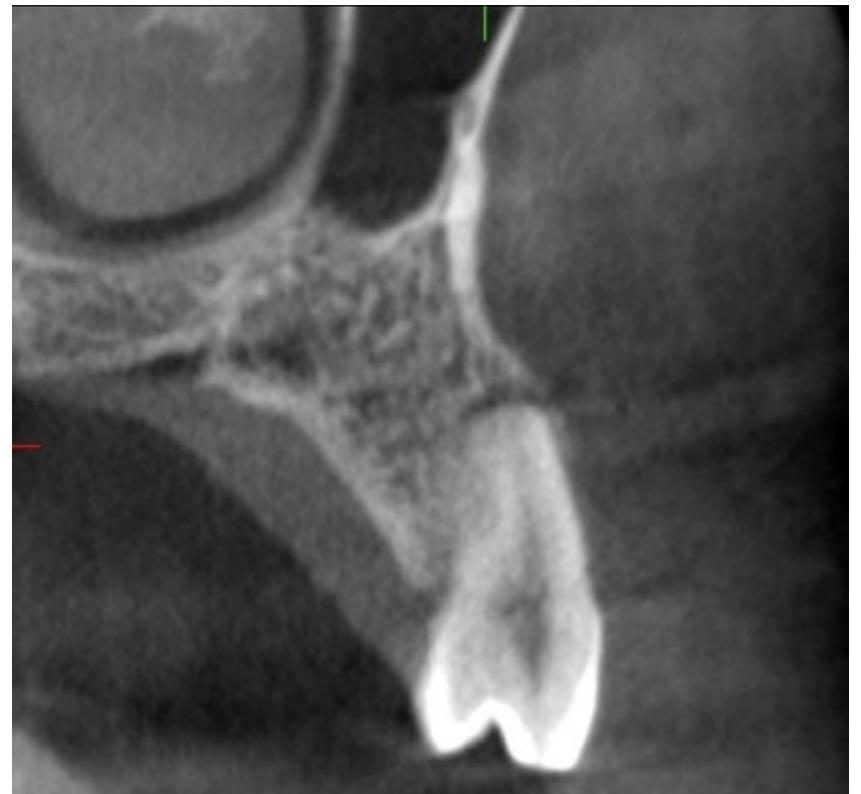

5 Zweiter Patientenfall. Dreidimensionale Darstellung der Wurzelstellung im Alveolarfortsatz

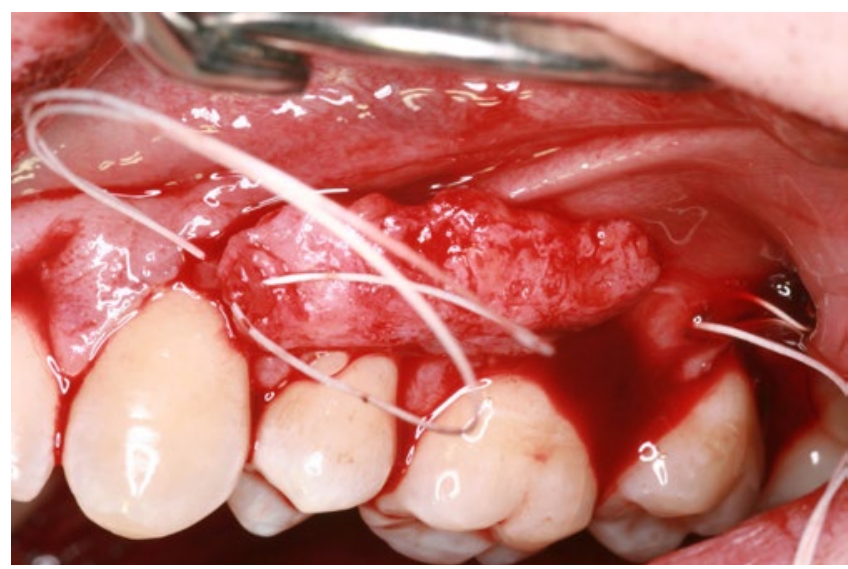

7 Zweiter Patientenfall. Mithilfe einer Hilfsnaht wird das Transplantat in den zuvor präparierten Tunnel eingebracht.

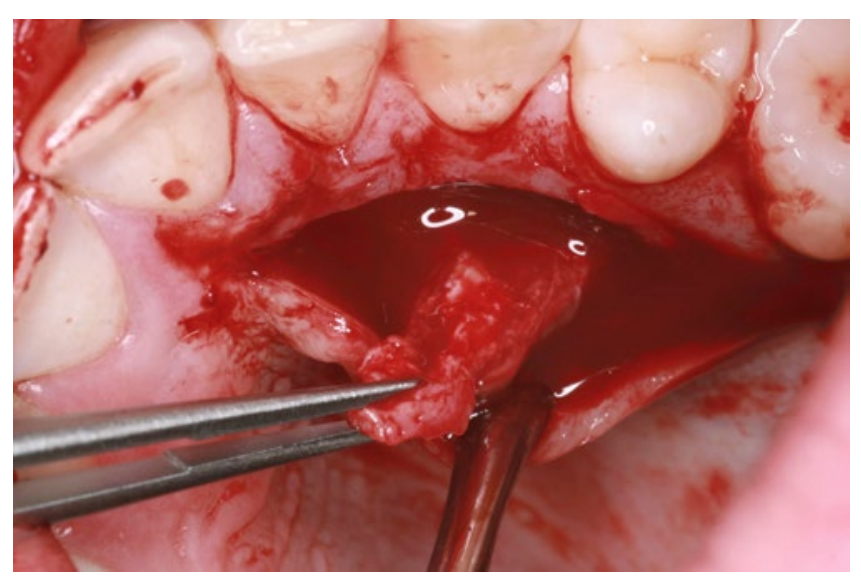

6 Zweiter Patientenfall. Entnahme eines Bindegewebstransplantats von der linken Gaumenseite

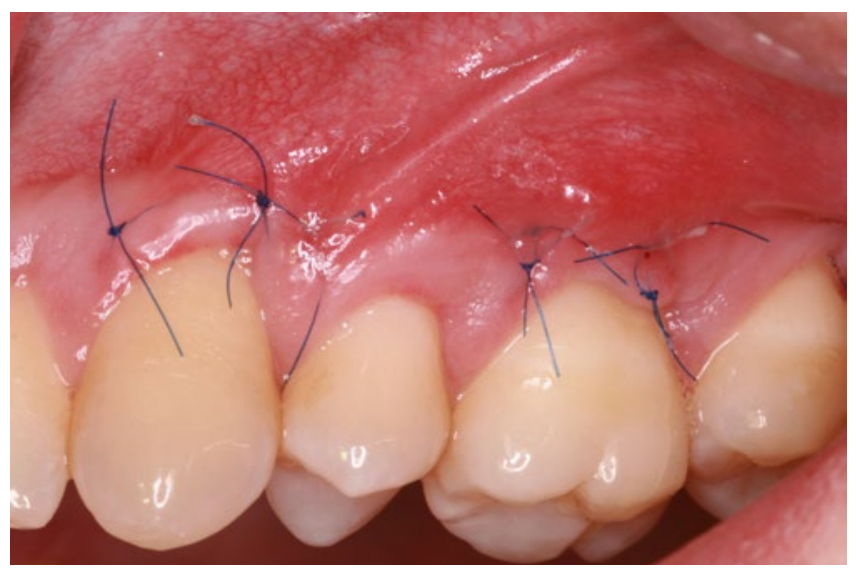

8 Zweiter Patientenfall. Trotz der ungünstigen Wurzelstellung konnte nach zwei Wochen eine deutliche Verbesserung mit einer vollständigen Deckung und einer Verbreiterung der keratinisierten Gingiva erzielt werden.

Wir bitten, die korrekte Abbildungs-Reihenfolge zu beachten und den Fehler zu entschuldigen.

Die Redaktion

\section{Korrespondenzadresse:}

\section{Dr. B. Greven, MSc}

Schwerpunktpraxis Parodontologie/Implantologie

Kösterbergstr. 1

22587 Hamburg-Blankenese

DrGreven@parodontologie-im-norden.de 